\title{
Effects of synthetic acaricides on honey bee grooming behavior against the parasitic Varroa destructor mite
}

\author{
Igor Medici de Mattos ${ }^{1,2}$, Ademilson E. E. SoARes ${ }^{1}$, David R. TARPY ${ }^{2}$ \\ ${ }^{1}$ Department of Genetics, Ribeirão Preto Medical School, University of São Paulo, 14.049-900, Ribeirão Preto, SP, Brazil \\ ${ }^{2}$ Department of Entomology, North Carolina State University, Raleigh, NC 27695, USA \\ Received 28 March 2016 - Revised 1 December 2016 - Accepted 10 January 2017
}

\begin{abstract}
Varroa destructor is currently one of the main threats for western apiculture. Today, synthetic acaricides (specifically coumaphos, amitraz, and tau-fluvalinate) are the most common methods to control Varroa infestations. These compounds, however, are frequently related to a wide range of side effects in the host, as well as a long halflife inside the hive matrices (wax and honey). The western honey bee, Apis mellifera, exhibits natural defense mechanisms against the mite such as grooming behavior, which is a sequence of bodily movements where the host scrapes its legs across its body surface to remove the mite. We tested the effects of synthetic acaricides on the performance of grooming behavior by adult honey bee workers. We found that acaricide exposure prior to grooming delayed grooming and reduced the overall duration of grooming behavior. Our data add to a list of other sublethal behavioral consequences of acaricides that may subvert a comprehensive approach to Varroa control in managed colonies.
\end{abstract}

\section{Apis mellifera / coumaphos / amitraz / tau-fluvalinate / grooming behavior / Varroa destructor}

\section{INTRODUCTION}

It is known that honey bee populations are in declining health in Europe and North America (vanEngelsdorp et al. 2008; Mutinelli et al. 2010; Seitz et al. 2016). It is likely that these colony losses result from a combination of multiple factors, including diminished wildflower diversity and habitat, exposure to pesticides, and numerous diseases and parasites (Desneux et al. 2007; Hawthorne and Dively 2011; Dainat et al. 2012; Williamson et al. 2014). Nowadays, the parasitic mite Varroa destructor is considered one of the main concerns for apiculture worldwide (De Jong et al. 1982; Le Conte et al. 2010; Rosenkranz et al. 2010). This ectoparasite feeds on the hemolymph of adults and developing bees,

Corresponding author: I. Mattos, igormmattos@usp.br Manuscript editor: Peter Rosenkranz vectoring viral pathogens, prompting malformations, undermining colony performance, and eventually resulting in colony death. The original host of $V$. destructor is the Eastern honey bee (Apis cerana), but it is believed that the mite host switched to Apis mellifera in the first half of the last century in regions where both species of bees were managed (Oldroyd 1999; Rosenkranz et al. 2010).

To this day, the most common practice to control Varroa is the use of in-hive acaricides (Ruffinengo et al. 2014; Mullin et al. 2010). Despite the often efficient Varroa control promoted by these chemicals, innumerous side effects have been observed. Two acaricides in particular, taufluvalinate and coumaphos, were ubiquitously prevalent in colonies and are frequently found at high concentrations (Mullin et al. 2010). Since the half-life of tau-fluvalinate and coumaphos is 5 years in wax (Bogdanov 2004), these pesticides can easily accumulate in colonies to reach unsafe levels (Haarmann et al. 2002; Mullin et al. 2010; 
Williamson et al. 2014; Zhu et al. 2014). Coumaphos is a neurotoxic organophosphate that inhibits acetylcholinesterase, thus interfering with nerve signaling and function (Boncristiani et al. 2012). Recent studies have shown that coumaphos can alter some immune and detoxification gene expression pathways (Boncristiani et al. 2012; Garrido et al. 2013), affect queen and drone reproductive quality (Pettis et al. 2004; Rangel and Tarpy 2016), and diminish lifespan (Boncristiani et al. 2012). The pyrethroid tau-fluvalinate, an isomer of fluvalinate, targets the sodium channels of mites and insects altering neuronal electrical activity (Dong 2007; Eiri and Nieh 2012; Schmehl 2014). Tau-fluvalinate has already been reported as impacting queen and drone performance and competitiveness (Sokol 1996; Rinderer et al. 1999). Locke et al. (2012) also found direct effects of this pyrethroid on honey bees by increasing susceptibility to deformed wing virus infection. Some antennal olfactory receptor neurons also seem to be strongly sensitive to this pyrethroid (Kadala et al. 2011). Both acaricides are applied by beekeepers through pesticide-impregnated plastic strips and is subsequently distributed throughout a colony by nestmate interaction and trophallaxis (vanBuren et al. 1992; Bevk et al. 2012).

Another known acaricide, amitraz, is a formamidine octopaminergic agonist that can also impact learning and cognition in honey bees (Loucif-Ayad et al. 2008; Boncristiani et al. 2012; Garrido et al. 2013). Amitraz was one of the first acaricides to be registered in the USA, although in 1994 the preparation was withdrawn from the market (Johnson et al. 2013). Amitraz was reported targeting receptors in either the nervous or neuromuscular systems (Evans 1980; Papaefthimiou et al. 2013). Now amitraz is reregistered in some states of the USA and frequently found in beeswax (Mullin et al. 2010; Johnson et al. 2010; Semkiw et al. 2013).

Another negative consequence of the indiscriminate use of acaricides to control Varroa infestation is the repeated selection of mites that are resistant to each of these compounds (Milani 1995; Elzen and Westervelt 2002; Maggi et al.
2012). It has also been demonstrated that combined exposure to pesticides may synergize, resulting in the compounds being even more toxic to honey bees than when administered individually (Johnson et al. 2010; Zhu et al. 2014; Johnson 2015). For example, pre-exposure to amitraz can increase the toxicity of other acaricides (Johnson et al. 2013). Evidently, these complex combinations of pesticides may produce synergistic effects on the insect nervous system, especially when they affect the same physiological targets (Johnson et al. 2009; Hawthorne and Dively 2011; Gill et al. 2012).

Controlled breeding programs aimed at Varroa resistance have been conducted in some European honey bee populations, in both Europe and North America and, in some cases, has reached satisfactory results (Rosenkranz et al. 2010; Rinderer et al. 2010; Büchler et al. 1992). These programs are based on selecting bees according to various traits and activities that were identified as mechanisms for tolerance to $V$. destructor infestation in A. mellifera, most of which are also evident in the original host species. These include hygienic behavior, grooming behavior, and suppressed mite reproduction (Peng et al. 1987; De Jong 1988; Büchler et al. 1992; Rath 1999; Rosenkranz et al. 2010). Grooming behavior is a response to $V$. destructor parasitism that consists of worker bees scraping their legs over their own body in order to remove the ectoparasite (auto-grooming) or by attacking them directly with their mandibles when they are detected on a nestmate's body (allogrooming) (Ruttner and Hänel 1992; Rosenkranz et al. 1997). As a result, the mites can be injured or even killed when successfully groomed (Bienefeld et al. 1999). This behavior appears to be age dependent, and highly specialized workers that frequently employ allogrooming behavior tend to never develop into foragers (Moore et al. 1995). Despite the recent discussion on the effectiveness of traits related to Varroa tolerant Varroa -sensitive hygienic (VSH) behavior (Danka et al. 2016), it is undeniable that the grooming behavior towards the ectoparasite promotes lower infestation rates (Rosenkranz et al. 2010; Rinderer et al. 2010).

Although much is known about the side effects of acaricides on bee health and toxicology, very 
little is known about the effects of miticides on the behavior of A. mellifera, especially the effects of sublethal doses on the innate Varroa-resistance activities. Here, we quantify the effects of different acaricides on honey bee workers' grooming behavior in an effort to elucidate the possible side effects of acaricides on the social immunity of this ectoparasite-host relationship.

\section{MATERIALS AND METHODS}

We obtained European honey bee workers from a single colony to control genotype, kept at the North Carolina State University Lake Wheeler Honey Bee Research Facility (Raleigh, North Carolina, USA; $35.7806^{\circ} \mathrm{N}, 78.6389^{\circ} \mathrm{W}$ ), by collecting them directly from brood frames. Immediately after sampling, we placed 20 sampled worker bees inside individual plastic cages ("holding cages") and fed 50\% sucrose solution ad libitum. We maintained the cages in a room with temperatures near broodnest conditions $\left(34{ }^{\circ} \mathrm{C}\right.$ and $\sim 50 \%$ $\mathrm{RH})$. Within each holding cage, we separately introduced a fraction of one of the three acaricides - coumaphos (CheckMite+ $\left.{ }^{\circledR}\right)$, amitraz
(Apivar $\AA$ ), or tau-fluvalinate (Apistan $\AA)$ - to avoid known synergistic interactions.

The total amount of the acaricide presented in each fragment was calculated through the area $\left(\mathrm{mm}^{2}\right)$ of each strip, according to manufacturer specifications of concentration and total amount of acaricide per strip.

The estimated mean amount of active ingredient to each tested bee was calculated by the total amount of acaricide per fractionated strip divided by the number of bees presented in each holding cage. Each fraction of acaricide strip used presented $0.5 \times, 1 \times, 5 \times$, and $10 \times$ the $\mathrm{LD}_{50}$ of the tested acaricides (according to the reference $\mathrm{LD}_{50}$ described by Dahlgren et al. 2012): amitraz, $2.8 \mu \mathrm{g} /$ bee (corresponding to $1.3 \mathrm{~mm}^{2}$ of one strip); coumaphos, $26 \mu \mathrm{g} /$ bee $\left(4.5 \mathrm{~mm}^{2}\right)$; and tau-fluvalinate, $20.3 \mu \mathrm{g} /$ bee $\left(4.2 \mathrm{~mm}^{2}\right)$. In doing so, we established a total of 13 groups (Table I), repeating each treatment at least three times.

\subsection{Behavioral assay}

We followed the behavioral bioassay for individual grooming as developed by Aumeier

Table I. All groups tested in this research and their respective acaricide treatments, concentration, and number of tested bees

\begin{tabular}{|c|c|c|c|c|c|}
\hline Group & Acaricide & Amount of acaricide ${ }^{a}$ & Number of bees & Number of repetitions & Total \\
\hline 1 & \multirow[t]{4}{*}{ Coumaphos } & 10 times $\mathrm{LD}_{50}$ & 20 & 3 & 60 \\
\hline 2 & & 5 times $\mathrm{LD}_{50}$ & 20 & 3 & 60 \\
\hline 3 & & 1 time $\mathrm{LD}_{50}$ & 20 & 3 & 60 \\
\hline 4 & & 0.5 times $\mathrm{LD}_{50}$ & 20 & 3 & 60 \\
\hline 5 & \multirow[t]{4}{*}{ Amitraz } & 10 times $\mathrm{LD}_{50}$ & 20 & 3 & 60 \\
\hline 6 & & 5 times $\mathrm{LD}_{50}$ & 20 & 3 & 60 \\
\hline 7 & & 1 time $\mathrm{LD}_{50}$ & 20 & 3 & 60 \\
\hline 8 & & 0.5 times $\mathrm{LD}_{50}$ & 20 & 3 & 60 \\
\hline 9 & \multirow[t]{4}{*}{ Tau-fluvalinate } & 10 times $\mathrm{LD}_{50}$ & 20 & 3 & 60 \\
\hline 10 & & 5 times $\mathrm{LD}_{50}$ & 20 & 3 & 60 \\
\hline 11 & & 1 time $\mathrm{LD}_{50}$ & 20 & 3 & 60 \\
\hline 12 & & 0.5 times $\mathrm{LD}_{50}$ & 20 & 3 & 60 \\
\hline Control & - & - & 20 & 5 & 100 \\
\hline Total & & & & 820 & \\
\hline
\end{tabular}

a The area of each one of the acaricides' strips were calculated according to the amount of active compound contained in each one of the tested strips, as well as the $\mathrm{LD}_{50}$ tested by Dahlgren et al. (2012) 
(2001). Briefly, we placed single bees inside individual transparent-plastic petri dishes $\left(145 \mathrm{~mm}^{2}\right)$ for at least $20 \mathrm{~min}$ to acclimate, after which we placed an adult female mite, collected directly from adult bees (from the same colony used as source of nurse bees), onto each bee's dorsal thorax with a paint brush. We did not use the same Varroa mite more than once. We tested bees after they spent 2, 4, 24, 28, 48, 52, and $72 \mathrm{~h}$ inside their respective holding cage. Each bee was tested just once for each time of exposure. No $V$. destructor mite was tested more than once.

We observed and video-recorded the subsequent activities of each bee for $3 \mathrm{~min}$ and posteriorly analyzed the frequencies and amount of time of five activities as variables for further statistical analysis: (1) time to react to the presence of a Varroa mite, recorded as the time ( $\mathrm{min}$ ) it took for a worker to react to the mite with grooming movements; (2) time spent grooming $(\mathrm{min})$ after we placed the Varroa mite onto its thorax; (3) attempts to fly, as many bees initiated flight behavior during the assay; (4) time spent motionless ( $\mathrm{min}$ ) without displaying any movement; and (5) time displaying motor coordination problems (MCP), defined as the time (min) spent by each tested bee upside down or displaying difficulty to remain on its legs (Oliver et al. 2015). These activities were chosen to be recorded in a pilot study since they were the most frequently observed activities. We considered "grooming behavior" (related to defense against the mite infestations) as scraping legs over the bee's body, shaking, and rolling (Aumeier 2001). We did not recorded movements performed to clean body parts that the Varroa mite was not present, such as antennae and mouth parts. Data from worker bees that appeared still paralyzed (after $20 \mathrm{~min}$ for acclimation), displayed grooming behavior before mite contact, or defecated while tested, were discarded (as in Aumeier 2001).

\subsection{Analyses}

We compared the behavioral data statistically through two-way ANOVA tests with Dunnet's tests as post hoc analyses. We also compared the mortality rates in each one of the treatment and control groups using survival analyses with nonparametric Kaplan-Meier survival tests. All statistics were analyzed with JMP® Pro v10.0 (SAS,
Cary, NC) and are reported as mean \pm SEM and with $\alpha=0.05$, unless otherwise noted.

\section{RESULTS}

\subsection{Behavioral data}

Data obtained from 100 bees tested without any acaricide exposure (control group), 215 exposed to different doses of coumaphos, 232 exposed to different levels of amitraz, and 184 exposed to different amounts of tau-fluvalinate were used for statistical analysis. A total of 731 female adult Varroa mites were used in this research.

The analysis of all treatments showed significant effects of both time of exposure to the miticide $(F=5.59 ; d f=6,52 ; P=0.0002)$ and miticide $\operatorname{dose}(F=9.94 ; d f=3,52 ; P<0.0001)$ on the time spent performing grooming behavior (Figure Fig. 1). The Dunnet's test, used as a post hoc comparison, shows that the mean time spent with grooming behavior by coumaphos-treated bees was significantly lower than in the control group (mean difference $=0.592 ; 95 \% \mathrm{CL}$ of difference $=0.262$ to $0.922 ; P<0.05$ ). The amitraztreated bees, as well as the fluvalinate-treated bees, did not show significant differences from the control group (control $\times$ amitraz: mean difference $=0.254 ; 95 \% \mathrm{CL}$ of difference $=-0.072$ to $0.581 ; P>0.05$; control $\times$ tau-fluvalinate: mean difference $=0.170 ; 95 \%$ CL of difference $=-0.166$ to $0.507 ; P>0.05$ ).

The time to react to the presence of the mite was significantly greater in acaricide-treated bees than in the control group (Figure 2). The two-way ANOVA also demonstrates that both time of exposure to the miticide $(F=6.76 ; d f=6,52$; $P<0.0001)$ and miticide dose $(F=25.71 ; d f=3$, 52; $P<0.0001)$ significantly influenced the time to respond. The post hoc test showed that the reaction time registered for the control group was significantly lower than the ones observed in the group treated with coumaphos (mean difference $=-1.845 ; 95 \% \mathrm{CL}$ of difference $=-2.385$ to $-1.306 ; P<0.05$ ), amitraz (mean difference $=-1.204 ; 95 \% \mathrm{CL}$ of difference $=-1.740$ to $-0.669 ; P<0.05$ ), and tau-fluvalinate (mean difference $=-1.420 ; 95 \% \mathrm{CL}$ of difference $=-1.971$ to $-0.869 ; P<0.05)$. 
$\square$ Control (CON) $\square$ Coumaphos (COU) $\square \quad$ Amitraz (AMI) $\square$ Tau-fluvalinate (TAU)

\section{Hours 4 Hours 24 Hours 28 Hours 48 Hours 52 Hours 72 Hours}

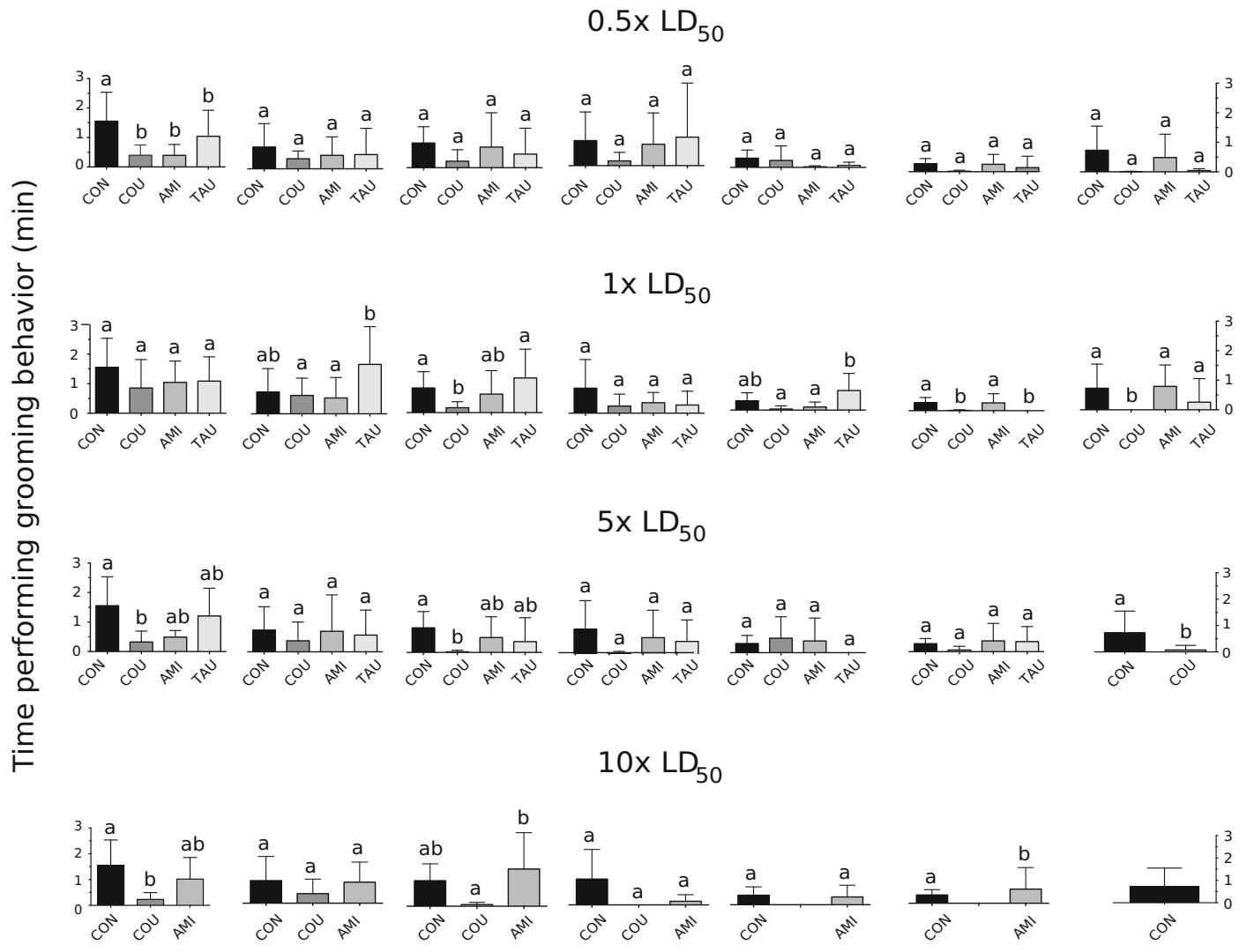

Figure 1. The mean time of performing grooming behavior by the tested honey bees, after being artificially infested with a live Varroa destructor mite, in the different treatments. Different letters indicate statistically significant difference (Dunnet's test).

The mean time displaying motor coordination problems presented by each treatment and control group presented no significant statistical interaction between time of exposure to the miticide. Miticide dose showed significant influence on this behavior $(F=2.79 ; d f=3,52$; $P<0.05)$. Pairwise comparison also showed that the mean time displaying motor coordination difficulties presented by the coumaphostreated group was significantly higher than that presented by bees from the control group (mean difference $=-0.242 ; 95 \%$ CL of difference $=-0.458$ to $-0.026 ; P>0.05)$. No significant differences were observed when comparing the mean time displaying motor coordination difficulties by the control group and the amitraz-treated, as well as the tau-fluvalinatetreated group.

The number of flight attempts seemed to not be influenced by neither time of exposure to the miticide nor miticide dose $(F=0.8595 ; d f=18$, 51; $P=0.625)$. Similarly, the mean time spent motionless was not affected by the time of exposure to the miticide or by the miticide dose $(F=0.91 ; d f=18,52 ; P=0.562)$.

\subsection{Survival analysis}

Bee mortality was higher in acaricide-treated groups than in the control group (Figure 3). The Kaplan-Meier survival test showed significant differences among the groups tested with acaricides 
口 Control (CON)

2 Hours 4 Hours 24 Hours 28 Hours 48 Hours 52 Hours 72 Hours

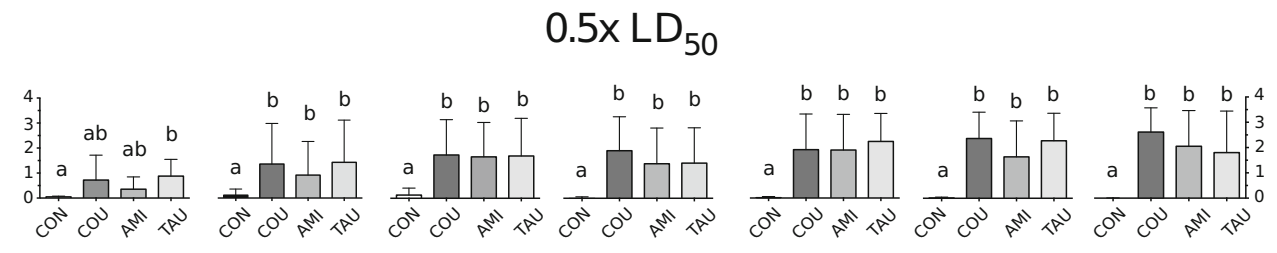

\section{$1 \times \mathrm{LD}_{50}$}

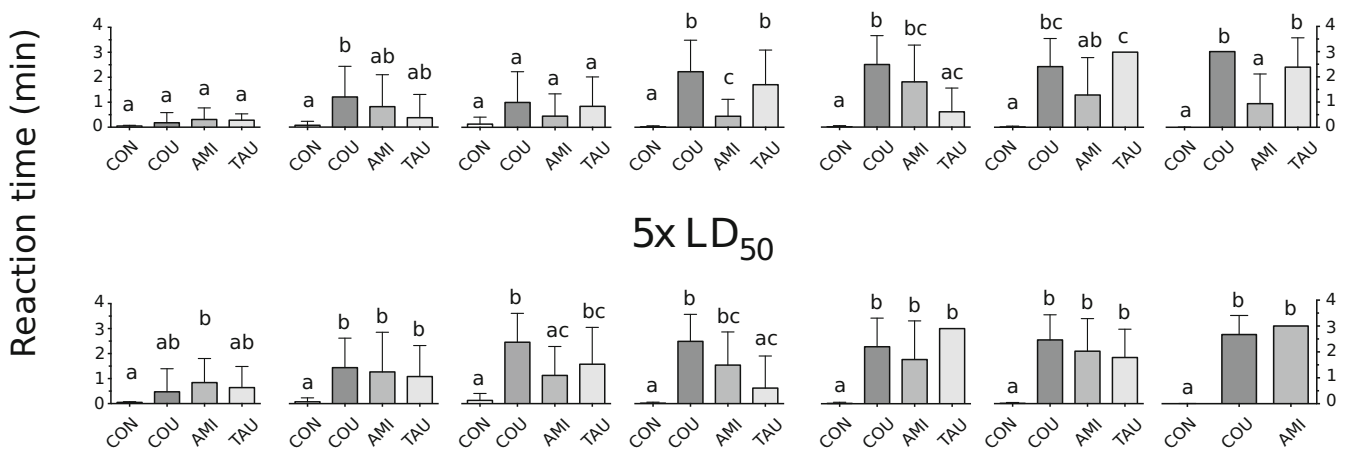

\section{$10 \times \operatorname{LD}_{50}$}
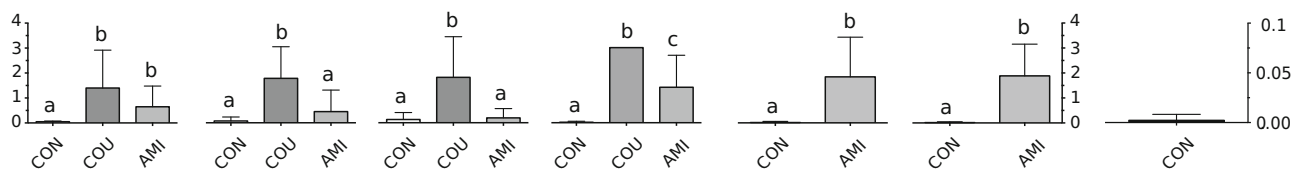

Figure 2. The mean time of reaction of the tested honey bees, after being artificially infested with a live Varroa destructor mite, in the different dose and time of exposure of three acaricides. Different letters indicate statistically significant difference (Dunnet's test).

$\left(0.5 \times, 1 \times, 5 \times\right.$, and $\left.10 \times \mathrm{LD}_{50}\right)$ and the control group (respectively: log-rank (Mantel-Cox): Chi square $=194.00, d f=3.0, P<0.0001 ;$ Chi square $=73.15, d f=3.0, P<0.0001 ;$ Chi square $=49.00, d f=3.0, P<0.0001 ;$ and $\mathrm{Chi}$ square $=153.021, d f=3, P<0.001)$.

Tau-fluvalinate resulted in the highest mortality among all the acaricides tested; in the highest dose $\left(10 \times \mathrm{LD}_{50}\right)$, the pyrethroid induced mortality within only $2 \mathrm{~h}$ of topical contact. Both coumaphos and tau-fluvalinate killed $100 \%$ of the tested bees within $72 \mathrm{~h}\left(10 \times \mathrm{LD}_{50}\right)$.

The pairwise comparison among the survival curves demonstrates that the control group had a higher survival rate than all the treatment groups
(Table II). Pairwise comparisons also showed that the mortality rates observed in the amitraz treatment $\left(5 \times, 1 \times\right.$ and $\left.0.5 \times \mathrm{LD}_{50}\right)$ were lower than those in the coumaphos and tau-fluvalinate treatments (Table II). No significant differences were observed when comparing the mortality rates between coumaphos and tau-fluvalinate (Table II).

\section{DISCUSSION}

The chemical control of Varroa has been important for the maintenance of beekeeping production as well as the pollination services performed by $A$. mellifera. The status quo of unsustainable colony losses, however, has been of great concern 


\section{X LD50}

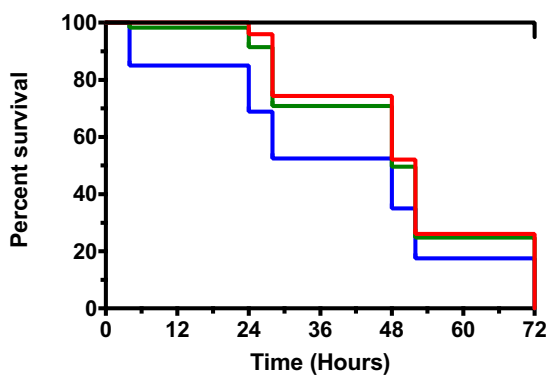

1X LD50

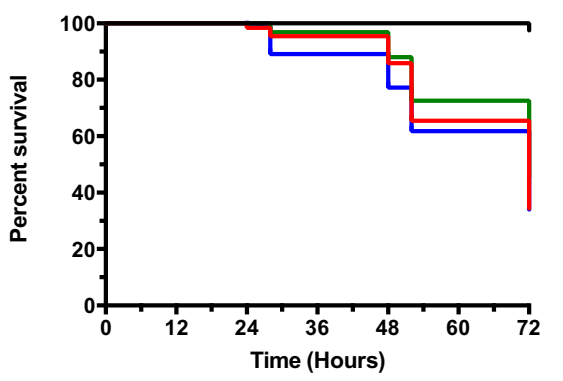

$5 X$ LD50

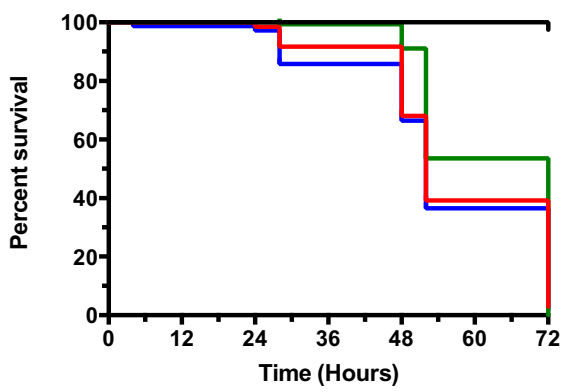

$0.5 X$ LD50

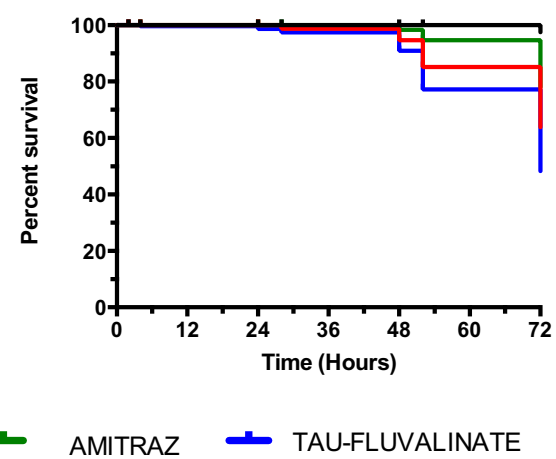

Figure 3. Survival curves observed for honey bees confined with three different acaricide treatments and their negative control group.

to beekeepers and the general public. The growing number of studies that highlight the side effects of acaricides (even in sublethal doses) and the long half-life presented by those chemicals (specially in wax) increases the priority for alternative Varroa control methods that are less harmful for bees (Mullin et al. 2010; Boncristiani et al. 2012; Locke et al. 2012; Williamson et al. 2014; Zhu et al. 2014). Mullin et al. (2010) found alarming concentration of acaricides contaminating colony wax, reaching up to $3.82 \mu \mathrm{g} / \mathrm{g}$ of amitraz, $91.9 \mu \mathrm{g} /$ $\mathrm{g}$ of coumaphos, and $188 \mu \mathrm{g} / \mathrm{g}$ of tau-fluvalinate. The combined exposure produced by Varroa control treatment and contaminated wax can produce doses higher than $\mathrm{LD}_{50}$ (such as the studied by Dahlgren et al. 2012). Our results show that all the tested synthetic acaricides have a significant effect on the survival of worker honey bees. In the highest dose tested $\left(10 \times \mathrm{LD}_{50}\right), 100 \%$ of the worker bees died within $72 \mathrm{~h}$. When subletal doses were applied $\left(0.5 \mathrm{LD}_{50}\right)$, the acaricide treatments resulted in death rates of $20 \%$ but still significantly higher than those in the control group. Compared with Dahlgren et al. (2012), the same dose of acaricide produced lower mortality rates (within $48 \mathrm{~h}$ ) in our tests. The differences observed are most likely a consequence of our different methods; we used fractions of acaricide strips inside cages instead of individual topical application of the active ingredient. Our approach may be subjected more to individual heterogeneity of the contacted dose, but it represents a more realistic facsimile of the in-hive exposure to the chemicals.

The side effects of these acaricides seem not to be restricted to mortality or contamination of beekeeping products, as important activities related to natural defense against Varroa were also significantly affected. Worker honey bees exposed to acaricide presented significantly less time spent performing grooming behavior after a Varroa mite was introduced onto its thorax.

Both the dose of the acaricides applied and the time of exposure presented significant effects on behavioral performance. Groups treated with 


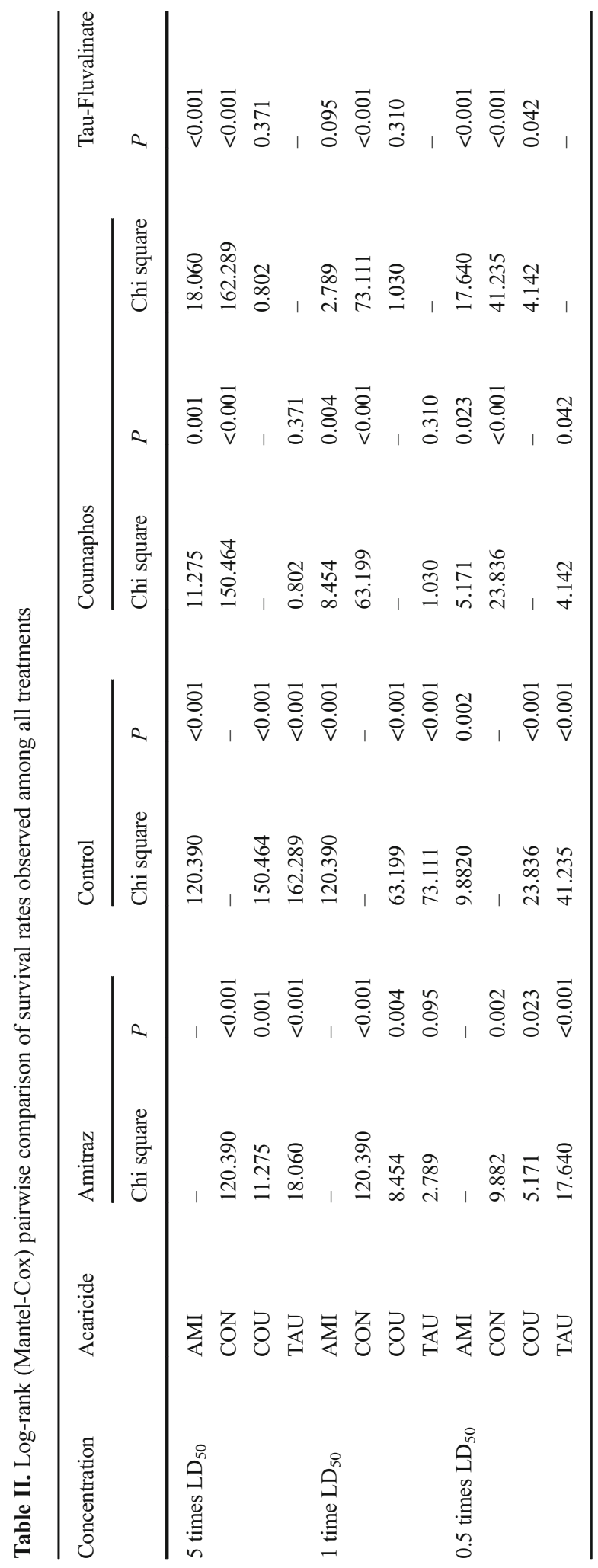


coumaphos presented the steepest reduction on the total time performing grooming behavior after the mite was introduced. Even at subletal doses, this organophosphate was able to significantly reduce grooming behavior. It is known that coumaphos has been reported to impact foraging behavior (Schneider et al. 2012), trophallaxis (Bevk et al. 2012), and motor activity (Williamson et al. 2013). Nonetheless, very little is known about the effects of this acaricide on natural Varroosis resistance, such as grooming. Williamson et al. (2013) observed a notable increase on grooming activity when coumaphos was fed to bees in sublethal doses. The authors observed the behavior of coumaphos-treated workers without the presence of the mite, as well as counted activities that are not directly related to attempts to remove the mite, such as grooming antennae. Considering the antagonistic results obtained by this research, as well as the differences in the experimental design, we may hypothesize that the presence of Varroa plays an important role in the triggering of grooming behavior (attempts to remove the mite) by the host.

The time it took for a worker bee to react with grooming movements to the presence of the mite on its body was also significantly affected by both the dose of the acaricide applied as well as the time each tested bee was exposed to the miticide. Groups treated with coumaphos and taufluvalinate exhibited significantly longer reaction times. Even at subletal doses, all acaricides dramatically increased the reaction time of the host.

Oliver et al. (2015) observed that bees exposed to tau-fluvalinate spent more time upside down and fanning their wings, although the authors did not find significant effects of tau-fluvalinate on grooming behavior. That experiment, however, was conducted in the absence of mites and is thus, once again, a notable difference from the experimental design adopted by the current study.

The behavioral side effects observed in acaricide-treated worker bees is concerning, considering that these activities are highly correlated to efficacy in grooming behavior against Varroa . Aumeier (2001) asserts that honey bee strains described as "efficient groomers" (e.g., Africanderived honey bees) display grooming movements for longer periods in the presence of the ectoparasite compared with susceptible strains (e.g., Carniolan European honey bees). The author also shows that efficient grooming performers react faster to the presence of the mite. de Mattos et al. (in review) similarly observed a significant positive statistical correlation between the total time performing grooming behavior and the resistance against Varroa in African-derived honey bees (as measured by total infestation rate). The same study also detected a highly significant negative correlation relating the time it took for a worker bee to initiate grooming movements.

It has been shown that the neurologic effects of acaricides may affect olfactory ability of antennae, cognition, learning, and memory in honey bees (Williamson et al. 2013). The neural circuits that drive olfactory learning and memory are all mediated by cholinergic neurotransmission (Gauthier 2010; Williamson et al. 2013). Substances able to disrupt acetylcholinesterase (such as coumaphos and amitraz) in the brain have been shown to produce significant impairments on those circuits (LoucifAyad et al. 2008; Williamson et al. 2013; Palmer et al. 2013). Frost et al. (2013) found that fluvalinate can also produce negative effects on honey bee olfactory learning and memory in their responsiveness to sucrose. Thus, it is possible that impairment of antennae olfactory sensitivity to cause delay on the process of triggering a fast grooming response. Rosenkranz et al. (2010) hypothesize that a specific scent of the mites could be detected by the bees then eliciting grooming movements. On the other hand, Kather et al. (2015) and Le Conte et al. (2015) highlight the ability of $V$. destructor to chemically mimicry host cues and avoid hygienic bees that would detect and remove the mites. Effects of acaricides on tactical sensitiveness of bees, as well as the role those tactical skills play on Varroa resistance, still need to be tested.

New studies are also required to better understand how acaricides impair the triggering and performance of grooming behavior, as well as the role played by olfactory sensitiveness, learning, and memory on the success of grooming defense against $V$. destructor .

The current study is not designed to determine which acaricide is the safest for Varroa control by beekeepers, although we illuminated a possible side effect of acaricide treatments against Varroa. 
It is also possible that our results indicate that chemical treatment can produce a scenario of dependence; when used, these acaricides can undermine the performance of naturally evolved mechanisms of defense against the mite (such as grooming behavior). The recurrent use of these acaricides can result in higher in-hive concentrations and consequently a possible sharp impairment of the performance of grooming against Varroa . According to this scenario, faster growth rates of mite populations, increasing the incidence of viruses, precocious weakening of colonies, and, consequently, higher rates of mortality can also be related to acaricide exposure.

We suggest that the discussion concerning the health status of the honey bee must address more narrowly the behavioral side effects of chemical treatments to mitigate Varroosis. Our data also imply that studies regarding natural defenses of the host against Varroa, as well as the ones addressing breeding honey bees for Varroa resistance, are important future directions for the development of sustainable beekeeping.

\section{ACKNOWLEDGEMENTS}

This research was funded by the Coordenação de Aperfeiçoamento de Pessoal de Nível Superior (CAPES) and grant 14-8130-0360-CA from the USDA-APHIS. We thank Jennifer Keller for her technical support in the field.

Contributions All authors equally contributed to this research accomplishment.

Effets d'acaricides de synthèse sur le comportement de toilettage de l'abeille contre l'acarien parasite Varroa destructor

Apis mellifera / coumaphos / amitraze / tau-fluvalinate / toilettage / Acari

Eindluss von synthetischen Akariziden auf das Grooming-Verhalten von Honigbienen gegenüber der parasitischen Varroamilbe

Apis mellifera / Coumaphos / Amitraz / tau-Fluvalinat / Grooming-Verhalten / Varroa destructor

\section{REFERENCES}

Aumeier, P. (2001) Bioassay for grooming effectiveness towards Varroa destructor mites in Africanized and Carniolan honey bees. Apidologie 32, 81-90.

Bevk, D., Kralj, J., Čokl, A. (2012) Coumaphos affects food transfer between workers of honeybee Apis mellifera. Apidologie 43, 465-470.

Bienefeld, K., Zautke, F., Pronin, D., Mazedd, A. (1999) Recording the proportion of damaged Varroa jacobsoni in the debris of honey bee colonies (Apis mellifera ). Apidologie 30, 249-256.

Bogdanov, S. (2004) Beeswax: quality issues today. Bee World 85, 46-50.

Boncristiani, H., Underwood, R., Schwarz, R., Evans, J. D., Pettis, J., vanEngelsdorp, D. (2012) Direct effect of acaricides on pathogen loads and gene expression levels in honey bees Apis mellifera. J Insect Physiol 58(5), 613-620.

Büchler, R., Drescher, W., Tornier, I. (1992) Grooming behaviour of Apis cerana, Apis mellifera and Apis dorsata and its effect on the parasitic mites Varroa jacobsoni and Tropilaelaps clareae. Exp Appl Acarol 16, 313-319

Dahlgren, L., Johnson, R. M., Siegfried, B. D., Ellis, M. D. (2012) Comparative toxicity of acaricides to honey bee (Hymenoptera: Apidae) workers and queens. J. Econ. Entomol. 105(6), 1895-1902.

Dainat, B., Evans, J. D., Chen, Y. P., Gauthier, L., Neumann, P. (2012) Predictive markers of honey bee colony collapse. PLoS ONE 7(2), e32151.

Danka, R.G., Harris, J.W., Dodds, G.E. (2016) Selection of VSH-derived "Pol-line" honey bees and evaluation of their Varroa -resistance characteristics. Apidologie 47 : doi:10.1007/s13592-015-0413-7.

De Jong, D. (1988) Varroa jacobsoni does reproduce in worker cells of Apis cerana in South Korea. Apidologie 19, 241-244.

De Jong, D., Morse, R. A., Eickwort, G. C. (1982) Mite pests of honey bees. Annu. Rev. Entomol 27(1), 229-252.

de Mattos, I. M., De Jong, D., Prata, M. A., Souza, J., Soares, A. E. E. A simplified grooming behavior bioassay predicts tolerance to Varroa destructor infestation in Africanized honey bee colonies. In review. Exp. Appl. Acarol

Desneux, N., Decourtye, A., Delpuech, J. M. (2007) The sublethal effects of pesticides on beneficial arthropods. Annu. Rev. Entomol. 52, 81-106.

Dong, K. (2007) Insect sodium channels and insecticide resistance. Invertebr. Neurosci. 7, 17-30.

Eiri, D., Nieh, J. C. (2012) A nicotinic acetylcholine receptor agonist affects honey bee sucrose responsiveness and decreases waggle dancing. J. Exp. Biol. 215, 2022-2029.

Elzen, P. J., Westervelt, D. (2002) Detection of coumaphos resistance in Varroa destructor in Florida. Am. Bee J. 142, 291-292. 
Evans, J. D. (1980) Gee, action of formamidine pesticides on octopamine receptors. Nature 287, 60-62.

Frost, E. H., Shutler, D., Hillier, N. K. (2013) Effects of fluvalinate on honey bee learning, memory, responsiveness to sucrose, and survival. J. Exp. Biol. Advance Online Articles. First posted online on 25 April 2013. doi:10.1242/jeb.086538

Garrido, P. M., Antúnez, K., Martín, M., Porrini, M. P., Zunino, P., Eguaras, M. J. (2013) Immune-related gene expression in nurse honey bees (Apis mellifera) exposed to synthetic acaricides. J. Insect Physiol. 59, 113-119.

Gauthier, M. (2010) State of the art on insect nicotinic acetylcholine receptor function in learning and memory. Adv. Exp. Med. Biol. 683, 97-115.

Gill, R. J., Ramos-Rodriguez, O., Raine, N. E. (2012) Combined pesticide exposure severely affects individual- and colony-level traits in bees. Nature 491, 105-108.

Haarmann, T., Spivak, M., Weaver, D., Weaver, B., Glenn, T. (2002) Effects of fluvalinate and coumaphos on queen honey bees (Hymenoptera: Apidae) in two commercial queen rearing operations. J. Econ. Entomol. 95 (1), 28-35.

Hawthorne, D. J., Dively, G. P. (2011) Killing them with kindness? In-hive medications may inhibit xenobiotic efflux transporters and endanger honey bees. PLosONE 6 (11), 1-9.

JMP®, Pro v10.0. SAS Institute Inc., Cary, NC, 1989-2007

Johnson, R. M. (2015) Honey bee toxicology. Annu. Rev. Entomol. 60, 415-34.

Johnson, R. M., Dahlgren, L., Siegfried, B. D., Ellis, M. D. (2013) Acaricide, fungicide and drug interactions in honey bees (Apis mellifera ). PLoS ONE 8(1), e54092.

Johnson, R. M., Ellis, M. D., Mullin, C. A., Frazier, M. (2010) Pesticides and honey bee toxicity-USA. Apidologie 41 (1), 312-331.

Johnson, R. M., Pollock, H. S., Berenbaum, M. R. (2009) Synergistic interactions between in-hive miticides in Apis mellifera. J. Econ. Entomol. 102, 474-479.

Kadala, A., Charreton, M., Jakob, I., Le Conte, Y., Collet, C. (2011) A use-dependent sodium current modification induced by type I pyrethroid insecticides in honeybee antennal olfactory receptor neurons. Neurotoxicology 32 (3), 320-30.

Kather, R., Drijfhout, F., Martin, S. (2015) Evidence for colony-specific differences in chemical mimicry in the parasitic mite Varroa destructor. Chemoecology 25, 215-222.

Le Conte, Y., Ellis, M., Ritter, W. (2010) Varroa mites and honey bee health: can Varroa explain part of the colony losses? Apidologie 41, 353-363.

Le Conte, Y., Huang, Z. Y., Roux, M., Zeng, Z. J., Christidès, J-P., Bagnères, A. G. (2015) Varroa destructor changes its cuticular hydrocarbons to mimic new hosts. Biol. Lett. 11, 20150233.

Locke, B., Conte, Y. L., Crauser, D., Fries, I. (2012) Host adaptations reduce the reproductive success of Varroa destructor in two distinct European honey bee populations. Ecol. Evol. 2 (6), 1144-1150.
Loucif-Ayad, W., Aribi, N., Soltani, N. (2008) Evaluation of secondary effects of some acaricides on Apis mellifera intermissa (Hymenoptera, Apidae): acetylcholinesterase and glutathione S-transferase activities. Eur. J. Sci. Res. 21 (4), 642-649.

Maggi, M., Peralta, L., Ruffinengo, S., Fuselli, S., Eguaras, M. (2012) Body size variability of Varroa destructor and its role in acaricide tolerance. Parasitol. Res. 110 (6), 2333-40.

Milani, N. (1995) The resistance of Varroa jacobsoni Oud. to pyrethroids - a laboratory assay. Apidologie 26, 415-429.

Moore, D., Angel, J. E., Cheeseman, I. M., Robinson, G. E., Fahrbach, S. E. (1995) A highly specialized social grooming honey bee (Hymenoptera: Apidae). J. Insect Behav. 8(6), 855-861.

Mullin, C. A., Frazier, M., Frazier, J. L., Ashcraft, S., Simonds, R., vanEngelsdorp, D., Pettis, J. S. (2010) High levels of miticides and agrochemicals in north American apiaries: implications for honey bee health. PLoS One 5 (3), e9754.

Mutinelli, F., Costa, C., Lodesani, M., Baggio, A., Medrzycki, P., Formato, G., Porrini, C. (2010). honey bee colony losses in Italy. J. Apic. Res. 49 (1), 119-120.

Oldroyd, B. P. (1999) Coevolution while you wait: Varroa jacobsoni, a new parasite of western honeybees. Trends Ecol. Evol. 14, 312-315.

Oliver, C. J., Softley, S., Williamson, S. M., Stevenson, P. C., Wright, G. A. (2015) Pyrethroids and nectar toxins have subtle effects on the motor function, grooming and wing fanning behaviour of honeybees (Apis mellifera ). PLoS ONE 10 (8), e0133733.

Palmer, M. J., Moffat, C., Saranzewa, N., Harvey, J., Wright, G. A., Connolly, C. N. (2013) Cholinergic pesticides cause mushroom body neuronal inactivation in honeybees. Nature Comm. 4, 16-34.

Papaefthimiou, C., Papachristoforou, A., Theophilidis, G. (2013) Biphasic responses of the honeybee heart to nanomolar concentrations of amitraz. Pestic. Biochem. Physiol. 107, 132-137.

Peng, Y. S., Fang, Y., Xu, S., Ge, L. (1987) The resistance mechanism of the Asian honey bee, Apis cerana Fabr., to an ectoparasitic mite Varroa jacobsoni Oudemanns. J. Invertebr. Pathol. 49, 54-60.

Pettis, J. S., Collins, A. M., Wilbanks, R., Feldlaufer, M. F. (2004) Effects of coumaphos on queen rearing in the honey bee, Apis mellifera. Apidologie 35, 605-610.

Rangel, J., Tarpy, D. R. (2016) The combined effects of miticides on the mating health of honey bee (Apis mellifera L.). J. Apic. Res. 54 (3), 275-283.

Rath, W. (1999) Co-adaptation of Apis cerana Fabr. and Varroa jacobsoni Oud. Apidologie 30, 97-110.

Rinderer, T., Harris, J. W., Hunt, G., de Guzman, L. (2010) Breeding for resistance to Varroa destructor in North America. Apidologie 41, 409-424.

Rinderer, T. E., de Guzman, L., Lancaster, V., Delatte, G., Stelzer, J. (1999) Varroa in the mating yard: the effects 
of Varroa jacobsoni and Apistan $®$ on drone honey bees. Am. Bee Journal 139 (2), 134-139.

Rosenkranz, P., Aumeier, P., Ziegelmann, B. (2010) Biology and control of Varroa destructor. J. Invert. Pathol. 103, S96-S119

Rosenkranz, P., Fries, I., Boecking, O., Stürmer, M. (1997) Damaged Varroa mites in the debris of honey bee (Apis mellifera L.) colonies with and without hatching brood. Apidologie 28, 427-437.

Ruffinengo, S. R., Maggi, M. D., Marcangeli, J. A., Eguaras, M. J., Principal, J., Barrios, C., De Piano, F., Mitton, G. (2014) Integrated pest management to control Varroa destructor and its implications to Apis mellifera colonies. Zootecnia Trop. 32 (2), 149-168.

Ruttner, F., Hänel, H. (1992) Active defense against Varroa mites in a carniolan strain of honeybees. Apidologie 23, $173-187$.

Schmehl, D. R. (2014) Teal PEA. Genomic analysis of the interaction between pesticide exposure and nutrition in honey bees (Apis mellifera). J. Insect. Physiol. 71, 177-190.

Schneider, S., Eisenhardt, D., Rademacher, E. (2012) Sublethal effects of oxalic acid on Apis mellifera (Hymenoptera: Apidae): changes in behaviour and longevity. Apidologie 43 (2), 218-225.

Seitz, N., Traynor, K. S., vanEngelsdorp, D., Steinhauer, N., Rennich, K., et al. (2016) A national survey of managed honey bee 2014-2015 annual colony losses in the USA. J. Apic. Res. 54 (4), 292-304.

Semkiw, P., Skubida, P., Pohorecka, K. (2013) The amitraz strips efficacy in control of Varroa destructor after many years application of amitraz in apiaries. J. Apic. Sci. 57 (1), 107-120.

Sokol, R. (1996) The influence of a multimonth persistence of Fluwarol in a hive of a honey bee colony. Medycyna Weterynaryjna 52, 718-720.

vanBuren, N. W. M., Marien, A. G. H., Velthuis, H. H. W. (1992) The role of trophallaxis in the distribution of Perizin in a honeybee colony with regard to the control of the Varroa mite. Entomol. Exp. et Appl. 65, 157-164.

vanEngelsdorp, D., Hayes, J. Jr., Underwood, R. M., Pettis, J. (2008) A survey of honey bee colony losses in the U.S., fall 2007 to spring 2008. PLoS One 3, e4071.

Williamson, S. M., Baker, D. D., Wright, G. A. (2013) Acute exposure to a sublethal dose of imidacloprid and coumaphos enhances olfactory learning and memory in the honeybee Apis mellifera. Invert. Neurosci. 13(1), 63-70.

Williamson, S. M., Willis, S. J., Wright, G. A. (2014) Exposure to neonicotinoids influences the motor function of adult worker honeybees. Ecotoxicology 23, 1409-1418.

Zhu, W., Schmehl, D. R., Mullin, C. A., Frazier, J. L. (2014) Four common pesticides, their mixtures and a formulation solvent in the hive environment have high oral toxicity to honey bee larvae. PLoS ONE 9(1), e77547. 